\begin{tabular}{|c|c|c|}
\hline $\begin{array}{l}\text { PKS } \\
\text { PUBLIC } \\
\text { KNOWLDEE } \\
\text { PROJECT }\end{array}$ & $\begin{array}{c}\text { Revista de GEOGRAFIA } \\
\text { (RECIFE) } \\
\text { nttp://www.revista.uffe.br/revistageografia }\end{array}$ & $\begin{array}{l}\text { OJS } \\
\frac{\text { OPEN }}{\text { OPENAL }} \\
\text { SYSTEMS }\end{array}$ \\
\hline
\end{tabular}

\title{
A CONSTRUÇÃO CONCEITUAL E ESPACIAL DOS TERRITÓRIOS NEGROS NO BRASIL
}

\author{
Azânia Mahin Romão Nogueira ${ }^{1}$ \\ ${ }^{1}$ Mestranda em Geografia na Universidade Federal de Santa Catarina.Email: azaniarn@yahoo.com.br
}

Artigo recebido em 25/08/2017 e aceito em 01/10/2017

\begin{abstract}
RESUMO
O território é um dos conceitos fundamentais da Geografia, enquanto que as relações raciais são essenciais para a compreensão das dinâmicas sociais brasileiras. Apesar disso, a raça não é tratada como conceito analítico do discurso hegemônico geográfico contemporâneo no Brasil, nem como variável estrutural da desigualdade sócioespacial na sociedade do país. Ainda assim, a produção acerca dos territórios negros é presente nas ciências humanas e neste artigo compartilhamos a discussão acerca destes com base na revisão bibliográfica feita durante nossa pesquisa de mestrado, buscamos contribuir na discussão referente à formação de territórios negros, tanto academicamente, como conceito, quanto materialmente, no espaço geográfico. Conseguimos perceber que, apesar da existência de contribuições de geógrafos como Renato Emerson dos Santos e Alex Ratts, a discussão conceitual acerca dos territórios negros está focalizada em outras ciências humanas, especialmente na antropologia. Já a formação espacial dos territórios negros não pode ser pensada de maneira dissociada de outros processos de urbanização, como a segregação urbana, e as relações raciais inerentes às dinâmicas sociais.
\end{abstract}

Palavras-chaves: Território negro. Segregação racial. Conceitos da Geografia.

\section{THE CONCEPTUAL AND SPATIAL CONSTRUCTION OF THE BLACK TERRITORIES IN BRAZIL}

\begin{abstract}
Territory is one of the fundamental concepts of Geography, while race relations are essential for the understanding of Brazilian social dynamics. Despite this, race is not treated as an analytical concept of the contemporary geographic hegemonic discourse in Brazil, nor as a structural variable of socio-spatial inequality in the country's society. Nevertheless, production about black territories is present in the human sciences and in this article we share the discussion about them based on the bibliographical revision made during our master's research, we seek to contribute in the discussion regarding the formation of black territories, both academically, as a concept, as well as materially, in the geographical space. We can see that, despite the contributions of geographers such as Renato Emerson dos Santos and Alex Ratts, the conceptual discussion about black territories is focused on other human sciences, especially on anthropology. Regarding the spatial formation of black territories, they cannot be conceived in a way that is dissociated from other urbanization processes, such as urban segregation, and the racial relations inherent of social dynamics.
\end{abstract}

Keywords: Black territory. Racial segregation. Concepts of Geography 


\section{INTRODUÇÃO}

Esse artigo integra nossa pesquisa de mestrado no Programa de Pós-graduação em Geografia da Universidade Federal de Santa Catarina, em que investigamos como se caracterizam os territórios negros e se eles existem em Florianópolis, Santa Catarina, a partir dos bairros que compõem o município. Aqui socializamos nossa discussão acerca do território negro como conceito e também a partir dos processos urbanos que o constituem.

Antes disso, é importante pontuar que ideologia racial brasileira pressupõe que vivemos numa nação miscigenada, em que, apesar da superação teórica do mito da democracia racial, a população é fruto da mistura homogênea entre índios, negros e brancos. Por muito tempo, esse discurso impediu uma discussão aprofundada das relações raciais em nossa sociedade, quadro que se modificou especialmente com a redemocratização do país ao fim da ditadura militar, no final da década de 1970, que possibilitou a reorganização política do Movimento Negro. Apesar dos avanços nas últimas décadas referentes à questão racial no Brasil, esta categoria ainda não é considerada estruturante da sociedade, inclusive na Geografia. Em boa parte fundamentada no materialismo dialético marxista, a Geografia brasileira tende a não discutir outros pontos além da classe social como fator da desigualdade sócio-espacial, naturalizando as desigualdades raciais e a forma em que os mecanismos que as mantêm atuam na sociedade. Dessa maneira, faz-se necessário o debate que considera a raça como variável desta desigualdade, considerando, como Milton Santos afirmou, que cada indivíduo "vale pelo lugar onde está: o seu valor como produtor, consumidor, cidadão, depende de sua localização no território" (SANTOS, 1987, p. 81). Corroborando com essa ideia, Carlos Walter Porto-Gonçalves discorre acerca das diferentes configurações espaciais resultantes do racismo presente nas relações da sociedade, que apresentam em sua geografia "lugares e espaços com as marcas dessa distinção social: no caso brasileiro, a população negra é francamente majoritária nos presídios e absolutamente minoritária nas universidades" (PORTO-GONÇALVES, 2003, pg. 2). Esses lugares ganham valores e, a partir deles, seus habitantes também são valorados e a raça é um dos fatores que define quais lugares serão prestigiados e quais serão estigmatizados, criando uma relação dialética entre território e lugar social.

A arquiteta e urbanista Raquel Rolnik apontou, no fim da década de 1980, a necessidade de mapear a "inserção territorial dos pretos e pardos nas cidades, seja localizando esse grupo mais precisamente no tecido urbano, seja penetrando em seus espaços cotidianos 
de vida e socialização" (ROLNIK, 2007, p. 75), mas poucos foram os esforços para fazê-lo em Florianópolis, pensando a população negra contemporânea. Pretende-se, com esta pesquisa, avançar no preenchimento dessa lacuna. Este debate é importante também para a própria população negra, como aponta Octavio Ianni (1987), ao dizer que para o branco é conveniente que a população negra não saiba quantos são, onde estão, como vivem e de que forma participam da renda, da cultura e das decisões políticas da sociedade.

A intenção desta pesquisa não é fazer um "recorte" ou apontar a presença negra como dissociada da identidade nacional, considerando que a população negra é majoritária no Brasil, como apontado pelo Censo Demográfico de 2010, dessa forma, ele próprio pode ser considerado um território negro, mas perceber como as relações raciais se apresentam na formação socioespacial.

Antonia dos Santos Garcia (2009) aponta o "paradoxo contemporâneo brasileiro" onde se reconhece a existência do racismo, mas não da existência de mecanismos sociais que perpetuam as desigualdades raciais. Em ressonância ao apontado por Garcia, Rafael Guerreiro Osório analisou as três ondas teóricas que tratam dos mecanismos de reprodução da desigualdade socioeconômica entre os grupos raciais no Brasil, observando o papel da academia no debate referente ao racismo.

A concepção de onda teórica foca nas principais ideias que distinguem cada uma, compreendendo que períodos e autores não podem ser limitados de forma rígida, já que existe diálogo entre intelectuais acerca do tema. Essa noção de onda, bem como a explicação de Osório sobre cada uma, nos será importante para entender as referências apresentadas nesta pesquisa, considerando que ela fala diretamente sobre a desigualdade racial refletida no espaço.

$\mathrm{Na}$ primeira onda, a tese principal defendida pelos autores é de que haveria preconceito de classe sem preconceito racial. Estes teóricos dão grande valor à miscigenação branqueadora, acreditando que, com o tempo, pardos ascenderiam socialmente. A presença, ainda que pequena, destes em posições sociais de destaque era tida como evidência tanto da permeabilidade quanto da ausência de preconceito.

$\mathrm{Na}$ segunda onda, é muito forte a ideia de que o preconceito de classe teria mais efeito na sociedade do que o de raça. Esse pressuposto, apesar da aparente superação da ideia do branqueamento racial da sociedade brasileira, ainda tem força em diversas linhas de pensamento, como na Geografia Crítica, em que, segundo Alex Ratts, as questões raciais 
tem pouca ressonância nos debates geográficos e, em específico, no ensino de Geografia, em face do primado de certas leituras do marxismo em que a classe social é considerada a principal variável, senão única da desigualdade socioespacial. (RATTS, 2010, pg. 128).

Apoiar a tese de que somente a classe é suficiente, ou principal categoria, para explicar as desigualdades sociais no Brasil é ser permissivo com o racismo, que afeta mais da metade da população nacional.

A terceira onda vem em reação à afirmação da inexistência, ou de efeitos leves, do preconceito racial no Brasil. Aqui, cor e posição social são vistos como indissociáveis e teriam a tendência de se perpetuar, caso não houvesse real ação para alterar o status quo. É daqui que vem a explicação considerada hegemônica atualmente sobre a persistência da desigualdade racial no Brasil. Carlos Hasenbalg e Nelson V. Silva, dois representantes desta onda, argumentam em sua obra conjunta "Estrutura Social, Mobilidade e Raça" que as práticas racistas que reproduzem a desigualdade racial não são apenas resquícios do passado escravocrata, e sim "funcionalmente relacionadas aos benefícios simbólicos e materiais que os brancos obtêm da desqualificação competitiva do grupo negro e mulato" (HASENBALG; SILVA, 1988, p. 166.). Também é característica desta onda o uso de dados estatísticos para embasar as pesquisas, como Edward Telles (1993) fez em suas pesquisas acerca da segregação racial no Brasil, onde analisou diversos municípios do país.

A presente pesquisa se alinha com os pressupostos defendidos pela terceira onda identificada por Osório, que percebe o racismo não apenas como fruto do passado colonial, mas como estruturador também da sociedade de classes. Consequentemente, não há dúvida no papel da classe social na distribuição da população negra no espaço, mas é indispensável a discussão a partir da raça para compreender a permanência dessa população nestes espaços.

Adotamos o Pensamento Decolonial como perspectiva teórica nesta pesquisa por entender que desejamos contribuir para a construção de outra ciência, rompendo epistemologicamente com a dominação no âmbito do conhecimento. Esse movimento epistemológico chama atenção para o legado do colonialismo, a Colonialidade, que permanece presente nas "estruturas e instituições e também nas mentalidades, imaginários, subjetividades e epistemologias, e até hoje dão forma e conteúdo às sociedades atuais" (ALMEIDA, SILVA, 2015, p. 47). Portanto, pensar decolonialmente é pensar também rompendo com os moldes da ciência europeia, compreendendo que as estruturas presentes na 
construção do conhecimento afetam o que é produzido na academia, mas vão além, atingindo as experiências cotidianas, ao, por exemplo, embasar políticas públicas.

Outro aspecto importante do Pensamento Decolonial, é que o mesmo vê as relações raciais como fator estruturante da sociedade moderna, pois percebe a ideia de raça como uma das formas pelas quais a Colonialidade se manifesta, e a América Latina como lugar geopolítico central para se pensar as formas de organização do mundo, rompendo com a lógica da crítica eurocêntrica ao eurocentrismo, ainda muito presente na Geografia contemporânea brasileira.

Apesar disso, não descartamos a importância dos avanços conquistados no campo acadêmico por outras perspectivas, de forma que utilizaremos cânones que se alinham em outras perspectivas teóricas, porém em uma leitura direcionada, tendo a raça como categoria analítica principal de nossa pesquisa.

Assim, apresentaremos o presente artigo em duas etapas. Na primeira, com base na revisão bibliográfica feita durante a pesquisa, buscamos contribuir na discussão referente à formação de territórios negros academicamente, como conceito. $\mathrm{Na}$ segunda, abordaremos territórios negros materialmente, no espaço geográfico.

\section{TERRITÓRIOS NEGROS: CONSTRUÇÃO CONCEITUAL}

A discussão conceitual acerca do território negro se inicia com o território, que é, junto com a paisagem, região, lugar e espaço, um conceito essencial para a Geografia, conforme argumenta Corrêa (2011).

O debate em torno do conceito na Geografia se inicia, segundo a historiografia europeia ocidental, com Ratzel no final do século XIX, e desde então passou por transformações decorrentes das mudanças epistemológicas na ciência geográfica ao longo da história.

Marcelo Lopes de Souza conceitua o território como "um espaço definido e delimitado por e a partir de relações de poder" (SOUZA, 2013, pg. 78). Esta interpretação de território é muito difundida atualmente na geografia hegemônica e é um dos elementos que motiva esta pesquisa, considerando essa necessidade de pensar o território e as relações de poder que o limitam além da classe social. Claude Raffestin (1993) afirma que poder é uma palavra rebelde e ambígua, fazendo parte da essência de todas as relações, sendo multidimensional e interescalar. Ele se opõe ao projeto do mundialismo homogeneizador, apontando que os 
mecanismos de reprodução das desigualdades raciais têm como objetivo perpetuar a dominação de um grupo sobre outro, a partir da inferiorização. O racismo é, portanto, uma forma de exercício do poder. Nesse sentido, Marta Araújo, Maria Paula Meneses e Sílvia Rodríguez Maeso afirmam que a abordagem positivista “constrói o racismo como irracionalidade e ignorância, enquanto simultaneamente evade a possibilidade de articulação de um discurso sobre a relação, historicamente construída, entre raça e poder" (ARAÚJO; MENESES; MAESO, 2010, pg. 116), portanto, falar do racismo como além de um desvio de caráter, fato histórico passado ou algo reproduzido apenas por grupos extremistas, e sim como uma força de poder estruturante da sociedade, é fundamental para identificá-lo e combatê-lo.

Robert David Sack caracteriza a territorialidade como "o meio pelo qual espaço e sociedade estão inter-relacionados" (SACK, 2011, pg. 63). Nesse sentido, consideramos aqui a territorialidade como o empoderamento de um território por um grupo e as estratégias de controle que o mesmo exerce, ou, como explicou Alicia Lindón, "o conjunto de relações tecidas pelo indivíduo, como membro de uma sociedade, com o seu entorno [...] é o que vincula o sujeito com seu lugar" (LINDÓN 2006 apud SILVEIRA, 2013, pg. 43). Essas formas de apropriação dos territórios negros estão intimamente relacionadas à identidade racial do grupo. Compreendemos a identidade negra como uma construção relativa que é pessoal, mas também coletiva, a partir de uma cultura comum percebida através de uma forma de organização social, em que os sujeitos são classificados por si próprios, mas também por e a partir de outros. María Laura Silveira afirma que "se podemos entender o território como a extensão apropriada e usada, a territorialidade pode ser definida como o sentido de pertencer àquilo que nos pertence" (SILVEIRA, 2013, pg. 39), ou seja, a construção da identidade também se faz a partir do território e vice-versa.

Nesse sentido, Bonnemaison e Cambrèzy afirmam que "o poder do laço territorial revela que o espaço está investido de valores não apenas materiais mas também éticos, espirituais, simbólicos e afetivos. É assim que o território cultural precede o território político e com ainda mais razão precede o espaço econômico" (BONNEMAISON; CAMBRÈZY, 1996 apud HAESBAERT, 2002, p. 50) deixando explícita a importância do pertencimento e da identidade ao falar de território.

João H. Costa Vargas nos lembra que a neutralidade não existe quando tratamos dos espaços urbanos, sendo estes "produtos de lutas históricas de poder, e as relações sociais derivadas de tais lutas tornam-se espacializadas de acordo com a ordem política hegemônica (...)” (VARGAS, 2005, p. 92). Desse modo, entendemos território como projeção espacial das 
relações de poder, como o racismo, no caso aqui estudado, incorporando também marcadores culturais que apoderam, a partir da identidade, o espaço no qual o território se manifesta.

Já a discussão acerca do conceito território negro propriamente dito transpassa diversas áreas do conhecimento. A socióloga Vera Lúcia Benedito, no texto intitulado "Cor e territórios na cartografia das desigualdades urbanas", é enfática ao afirmar que "entre os estudiosos do território urbano não há consenso quanto à definição de 'território negro"” (BENEDITO, 2013, p. 98) e ela explica a presença negra por si só não define território negro, pois:

não há um só bairro ou distrito na cidade onde a presença negra ou afrodescendente seja $100 \%$ [da população]. Mas é justamente na inscrição ou marcadores culturais e simbólicos que a predominância racial se acentua, por meio de organizações sociais, culturais e políticas as quais efetivam um devir e identidades de memória coletiva negra e afrodescendente. É no percurso do tempo e espaço que a história coletiva, marcada por carências sociais, mas também por articulações de lutas, e os microterritórios étnicos e raciais justificam sua razão de ser. (BENEDITO, 2013, p. 99).

Esse aspecto é relevante à discussão especialmente no caso brasileiro, em que, diferentemente do observado nos Estados Unidos ou na África do Sul, a segregação racial não é resultante de uma política de estado coexistente, e sim do racismo presente na sociedade. Dessa forma, territórios exclusivamente compostos por negros são raros no Brasil, considerando que outros fatores, como a segregação social, também atuam sobre o espaço. Assim, são outros elementos que caracterizam os territórios negros, que Benedito chama de "marcadores culturais e simbólicos". Estes marcadores, que podem ser organizações sociais, como ONGs do Movimento Negro; culturais, como escolas de samba, grupos de capoeira, clubes negros, bailes de música negra, rodas de samba e pagode; religiosas, como irmandades negras e terreiros de religiões de matriz africana; políticas, que vão desde atuação de partidos, como a Frente Negra, na década de 1950, até a posição de poder dentro destes territórios ocupada por negros, como líderes religiosos, políticos, moradores antigos ou de maior prestígio social, comerciantes, professoras, benzedeiras e parteiras.

Complementando esta ideia vem o antropólogo José Maurício Andion Arruti, que fala em territórios negros ao tratar de comunidades quilombolas rurais, utilizando o conceito de "memórias rituais", referindo-se a elementos que carregam "a própria identidade do grupo" (ARRUTI, 2016, p. 06). Agregamos, portanto, aspectos rotineiros, que fazem parte da 
coletividade daquele território em sua construção histórica. Celebrações culturais e de devoção, formas de organização socioespacial e outros costumes que formam a identidade coletiva dos ocupantes do território também são fatores que o constituem.

A também antropóloga Maria de Lourdes Bandeira ao estudar Vila Bela, em Mato Grosso, afirma que a cidade é um espaço negro e "esse espaço étnico localizava geograficamente uma territorialidade negra reconhecida, legitimada e acordada entre brancos e negros na região." (BANDEIRA, 1988, p. 43), notando-se as relações de poder se efetivando no processo de validação daquele território tanto por aqueles que nele se identificavam, quanto por aqueles que a ele não pertenciam. Mais tarde, Bandeira (1990) fala como a territorialidade negra é referida na identidade coletiva deste grupo, não de uma apropriação individualizada. Portanto, os territórios negros são construídos na alteridade, mas também são construídos na coletividade, a partir das relações internas a eles.

O geógrafo Renato Emerson dos Santos (2012) não trata de territórios negros diretamente no artigo "Sobre especialidades das relações raciais: raça, racialidade e racismo no espaço urbano", mas discorre acerca das expressões espaciais geradas pela segregação racial, que ajudam a pensar nos marcadores dos territórios negros, como clubes, escolas de samba e batalhas de rap. $\mathrm{O}$ autor também aborda toponímia da resistência, onde alusões à África e figuras afro-brasileiras se fazem presentes nos nomes de localidades de referência ou larga presença da população negra, como o Morro do Quilombo, em Florianópolis.

A antropóloga Ilka Boaventura Leite traz importante colaboração para a discussão conceitual de territórios negros. Ela inicia afirmando que

\footnotetext{
apesar da tendência de se intitularem 'territórios negros', quando pensados na sua dimensão política, a partir da ótica da RESISTÊNCIA, ou seja, como forma de defesa organizada numa situação de conflito, de tensão étnica e social e principalmente como suporte sob o qual se assentam atitudes coletivas de enfrentamento, a noção genérica de território negro não esclarece a complexidade das formas de apropriação do espaço por estes grupos (LEITE, 1990, p. 40).
}

O destaque ao termo "resistência" dado pela autora corrobora a ideia de que os territórios negros não são fruto de um isolamento auto induzido ou sem motivação, e sim uma "forma de defesa" frente ao racismo. Leite então se propõe a classificar os territórios negros em dois grupos, para expor a complexidade das estratégias de resistência desse grupo racial: os territórios de ocupação residencial, que se caracterizam por serem fixos, demarcados geograficamente por fronteiras de ocupação territorial, sendo que estes podem ou não ser Nogueira 2018 ISSN 0104-5490 211 
documentados legalmente, onde seus ocupantes se utilizam de estratégias coletivas para sua subsistência, através de códigos específicos de sociabilidade; e os territórios de ocupação interacional, que são pontos de encontro e troca, nem sempre fixos, mas caracterizados por códigos simbólicos.

A categorização proposta por Leite como territórios de ocupação interacional vai ao encontro do que Marcelo Lopes de Souza (2011) chama de territórios cíclicos, onde o território se desloca ou se transforma durante um curto período de tempo, como por exemplo, o Largo da Alfândega, que semanalmente torna-se um território de ocupação interacional ao receber a maior batalha de rap do município de Florianópolis. Esse território se transforma a partir dos diversos sujeitos que se apoderam do espaço, legitimados pelos seus pares, expressando as relações de poder que se desenham na dinâmica do município.

Já os códigos específicos de sociabilidade dos territórios de ocupação residencial, se assemelham com as ideias de marcadores identitários e de memórias rituais percebidos nas demais conceituações apresentadas, aspectos cotidianos das práticas dos sujeitos.

O geógrafo Alex Ratts, ao analisar o pensamento geográfico na produção da antropóloga Lélia Gonzalez, discute o lugar de negro resultado da segregação racial e espacial, e lugar negro resultado do reconhecimento desse grupo em um determinado espaço. Essa diferenciação é interessante por apontar a naturalização presente na sociedade brasileira de alocar os negros em lugares com menos prestígio ao mesmo tempo em que combate tal estigma, ao valorizar o lugar negro, aquele em que este grupo racial ocupa por identificação. Ratts ainda traz sua própria contribuição para o debate acerca do território negro, afirmando que eles são espaços “apropriados, marcados, qualificados, por grupos negros, ainda que não sejam exclusivos" (RATTS, 2012, p. 232) em acordo com as proposições expostas até aqui.

Portanto, compreendemos territórios negros como aqueles que são definidos a partir de relações de poder focadas na perspectiva racial, onde a identidade negra se faz presente, seja pela autodeclaração daqueles que se apropriam daquele espaço, mesmo que não de forma absoluta, seja pela presença de marcadores, como os apresentados aqui. Os territórios negros diferenciam-se não apenas pela simples presença de pessoas negras, mas pelos processos de identificação territorial pela qual essas pessoas se apreendem destes espaços, caracterizandose pela resistência à colonialidade. Sendo assim, é possível falar de territórios negros mesmo quando falamos de espaços onde a população é majoritariamente negra, como no Brasil, pois não se trata de um processo de formar guetos em espaços brancos. 


\section{TERRITÓRIOS NEGROS: CONSTRUÇÃO ESPACIAL}

A formação dos territórios negros não pode ser pensada de maneira dissociada de outros processos de urbanização, como a segregação racial, que é a representação espacial do racismo. Como o racismo tem formas diversas de se expressar na sociedade, é com a mesma multiplicidade que a segregação racial se apresenta. Um exemplo é o caso estadunidense, que tem uma manifestação do racismo considerada mais "explícita", consequentemente, a segregação racial lá é mais perceptível, com a formação dos guetos, que se mantiveram mesmo após a legitimidade política da organização racial promovida pelo Estado a partir das leis segregacionistas existentes anteriormente à década de 1960. Raquel Rolnik diz que o gueto estadunidense "sintetiza a imagem de discriminação racial aberta e da dominação branca" (ROLNIK, 2007, p. 75).

No Brasil, os guetos não existem com tanta abundância, o que fez muitas das interpretações da segregação urbana responsabilizarem as diferenças de classe pela desigualdade na distribuição espacial da população. O sociólogo estadunidense Edward Telles (1993) mensurou a segregação racial em 35 regiões metropolitanas brasileiras, incluindo Florianópolis, a partir dos dados do Censo Demográfico de 1980, separando a população em faixas de acordo com seu estrato social. Assim, era possível vislumbrar se o fator raça teria papel na segregação urbana. Telles percebeu graus de segregação menores do que em sua terra natal, porém presentes e que se agravavam nas faixas de renda mais altas, verificando que a raça de fato se coloca como um elemento que promove desigualdades no Brasil.

Milton Santos (1979) afirma que as cidades vão se tornando mais exclusivas e mais rígidas, tanto em suas formas quanto em suas funções e suas localizações, enquanto Antonia dos Santos Garcia (2012) aponta que a cidade é pensada a partir da lógica machista e racista desde a sua gênese. Com isso, podemos afirmar que raça e gênero são alguns dos elementos que marcam a exclusão nas cidades, portanto falar em segregação urbana é, obrigatoriamente, falar em segregação racial, entre outras. Esse passo é fundamental para que a literatura acadêmica rompa com o papel de normatizadora de desigualdades raciais, como observamos no discurso hegemônico vindo dos trabalhos acerca urbanização e discussões decorrentes.

Manuel Castells e Jordi Borja (1997) falam da segregação como consequência das opressões que minorias étnicas sofrem, mas também como resultando de uma reação defensiva e da especificidade cultural desses grupos, visto que dessa forma podem se proteger destas opressões usando da coletividade e afirmação racial como estratégia de resistência. É 
importante relembrar que, tradicionalmente, na literatura acerca da segregação racial, fala-se constantemente em minorias étnicas, porém, no Brasil observamos uma segregação da maioria da população promovida por um grupo étnico menor, mas com maior poder político e econômico, semelhante ao que foi observado na África do Sul durante o apartheid.

A formação de territórios negros é possibilitada a partir de diversos mecanismos econômicos, institucionais e culturais resultantes da expansão urbana, como a especulação imobiliária e o déficit habitacional, que se retroalimentam. Esses processos aprofundam a segregação, visto que a população é afastada para as periferias, áreas onde o acesso aos serviços e bens são mais caros, valorizando ainda mais os centros. Nesse sentido, Santos aponta que

A cidade em si como relação social e como materialidade, torna-se criadora de pobreza, tanto pelo modelo socioeconômico, de que é o suporte, como por sua estrutura física, que faz dos habitantes das periferias pessoas ainda mais pobres. A pobreza não é apenas o fato do modelo socioeconômico vigente, mas, também do modelo espacial. (SANTOS, 2005, p. 10).

\title{
NOTAS FINAIS
}

Não é objetivo desta pesquisa desqualificar a existência das desigualdades de classe e das ferramentas que o sistema capitalista utiliza para mantê-las, mas de perceber que estas desigualdades não são as únicas existentes nele. Compreendemos que, apesar de terem origens distintas, o capitalismo é simultaneamente sustentado e sustentador do racismo. Além disso, como aponta Anibal Quijano,

\begin{abstract}
é pertinente sair da teoria eurocêntrica das classes sociais e avançar para uma teoria histórica de classificação social. O conceito de classificação social, nessa proposta, refere-se aos processos de longo prazo nos quais os indivíduos disputam pelo controle dos meios básicos de existência social e de cujos resultados se configura um padrão de distribuição do poder centrado em relações de exploração/dominação/conflito entre a população de uma sociedade e em uma história determinada. (QUIJANO, 2010, pg. 112, tradução nossa).
\end{abstract}

Peter Marcuse diz que a segregação espacial pode ser definida como o "processo pelo qual um grupo população é forçado - isto é, involuntariamente - a se agrupar em uma área espacial definida, num gueto. É o processo de formação e manutenção de um gueto" 
(MARCUSE, 2001, pg. 03, tradução nossa). Portanto, tanto a concentração de negros nas periferias, como a ausência deles em bairros centrais, são reflexos desse processo que tem suas raízes nas desigualdades raciais.

Jurema Werneck, do Instituto da Mulher Negra Geledés conceitua o racismo institucional (ou sistêmico) como um “mecanismo estrutural” pelo qual o racismo:

garante a apropriação dos resultados positivos da produção de riquezas pelos segmentos raciais privilegiados na sociedade, ao mesmo tempo em que ajuda a manter a fragmentação da distribuição destes resultados no seu interior. O racismo institucional ou sistêmico opera de forma a induzir, manter e condicionar a organização e a ação do Estado, suas instituições e políticas públicas - atuando também nas instituições privadas, produzindo e reproduzindo a hierarquia racial. (WERNECK, 2013,pg. 17).

Dessa forma, a não distribuição igualitária das conquistas sociais onde a raça é o fator que determina a exclusão, como observamos nesta dissertação, deve ser combatida. O primeiro passo é assumir existência do racismo sistêmico que permeia as instituições brasileiras, pois elas são, concomitantemente, produto e reprodutoras das relações raciais de nossa sociedade. O segundo passo é o enfrentamento ao problema, através de políticas públicas e ações afirmativas, além da avaliação das mesmas e seus resultados. A produção acadêmica que analise dados e construa informações que embasem a ação do Estado é fundamental, nesse sentido, esperamos que esta dissertação venha a contribuir com a luta antirracista. Sendo a segregação racial um reflexo espacial das desigualdades raciais, esta pode ser transformada pela nossa sociedade a partir de mudanças de ordem estruturais.

\section{REFERÊNCIAS}

ALMEIDA, Eliene Amorim de; SILVA, Janssen Felipe da. Abya Yala Como Território Epistêmico: Pensamento Decolonial Como Perspectiva Teórica. Interritórios, Caruaru, v. 1, n. 1, p.42-64, 2015.

ARAÚJO, Marta; MENESES, Maria Paula; MAESO, Sílvia Rodríguez. Racismo e cidadania. Janus: Meio século de independências africanas, Lisboa, v. 31, n. 14, p.116-117, jan. 2010. Anual. Disponível em: <http://janusonline.pt/arquivo/2010/2010.html>. Acesso em: 19 abr. 2017. 
ARRUTI, José Maurício Andion. Territórios negros. Disponível em: $<$ http://www.geografia.fflch.usp.br/graduacao/apoio/Apoio/Apoio_Valeria/flg0563/1s2011/Te rritorios_Negros.PDF>. Acesso em: 10 dez. 2016.

BANDEIRA, Maria de Lourdes. Território negro em espaço branco: estudo antropológico de Vila Bela. São Paulo: Brasiliense; Brasília, DF: CNPq, 1988. 346p

BASTOS, José Messias. Urbanização, comércio e pequena produção mercantil pesqueira na Ilha de Santa Catarina. In: SANTOS, Maurício Aurélio dos (Org.). Ensaios sobre Santa Catarina. Florianópolis: Letras Contemporâneas, 2000a. p. 127-40.

BENEDITO, Vera Lúcia. Cor e territórios na cartografia das desigualdades urbanas. In: OLIVEIRA, Reinaldo José de (Org.). A cidade e o negro no Brasil: Cidadania e território. São Paulo: Ed. Alameda, 2013. p. 95-127

BRASIL. IBGE. Censo Demográfico, 2000. Disponível em: <www.ibge.gov.br>

CARDOSO, Vitor Hugo Bastos Cardoso; MAMIGONIAN, Beatriz Gallotti. Tráfico de escravos e a presença africana na Ilha de Santa Catarina. In: MAMIGONIAN, Beatriz Gallotti; VIDAL, Josiane Zimmermann (Org.). História diversa: africanos e afrodescendentes na Ilha de Santa Catarina. Florianópolis: Ed. da UFSC, 2013. p.17-42.

CASTELLS, Manuel; BORJA, Jordi. La ciudad multicultural. La factoría, n. 2, 1997.

CORREA, Roberto Lobato. Espaço: um conceito-chave da geografia. In: CASTRO, Iná Elias de; GOMES; Paulo César da Costa; CORRÊA, Roberto Lobato. Geografia: conceitos e temas. 14 ed. Rio de Janeiro: Bertrand Brasil, 2011, p. 15-48

GARCIA, Antonia dos Santos. Desigualdades raciais e segregação urbana em antigas capitais: Salvador, cidade D'Oxum, Rio de Janeiro, cidade de Ogum. Rio de Janeiro: Garamond, 2009.

HAESBAERT, Rogério. Concepções de território para entender a desterritorialização. In: SANTOS, Milton; BECKER, Bertha. (orgs.). Territórios, territórios: ensaios sobre o ordenamento territorial. Rio de Janeiro, DP\&A, 2002. p. 43-70.

HASENBALG, Carlos; SILVA, Nelson do Valle. Estrutura social, mobilidade e raça. Rio de Janeiro: Instituto Universitário de Pesquisas do Rio de Janeiro, 1988. 200 p.

IANNI, Octavio. Raças e classes sociais no Brasil. São Paulo: Brasiliense, 1987.

LEITE, Ilka Boaventura. Descendentes de africanos em Santa Catarina: invisibilidade histórica e segregação. In: LEITE, Ilka Boaventura. (Org.). Negros no Sul do Brasil: invisibilidade e territorialidade. Florianópolis: Letras Contemporâneas, 1996, p. 33-53. 
MARCUSE, Peter. Enclaves yes, ghettoes, no: segregation and the State. International Seminar on Segregation and the City, Cambridge, Lincoln Institute of Land Policy, 2001.

OSORIO, Rafael Guerreiro. Desigualdade racial e mobilidade social no Brasil: um balanço das teorias. In: THEODORO, $\mathrm{M}(\mathrm{Org}$.). As políticas públicas e a desigualdade racial no Brasil: 120 anos após a abolição. Brasília; IPEA, 2008. P 65-96.

PORTO-GONÇALVES, Carlos Walter. Prefácio: A Geografia do sistema mundo modernocolonial numa perspectiva subalterna. In: SANTOS, Renato Emerson dos (Org.). Diversidade, espaço e relações étnico-raciais: o negro na geografia do Brasil. Belo Horizonte: Autêntica, 2007. p. 07-12.

QUIJANO, Aníbal. Colonialidad del poder y clasificación social. In: CASTRO-GÓMEZ, Santiago; GROSFOGUEL, Ramón (Comp.). El giro decolonial: reflexiones para una diversidad epistémica más allá del capitalismo global. Bogotá: Siglo del Hombre Editores, 2007. p. 93-126. (Serie Encuentros). Disponível em: <http://www.unsa.edu.ar/histocat/ hamoderna/grosfoguelcastrogomez.pdf $>$. Acesso em: 17 jun. 2017.

RAFFESTIN, Claude. Por uma Geografia do Poder. São Paulo: Ática, 1993.

RATTS, Alex. Geografia, relações étnico-raciais e educação: a dimensão espacial das políticas de ações afirmativas no ensino. Revista Terra Livre. Ano 26, v. 1, n. 34, p. 125-140. 2010. Disponível em: http://www.agb.org.br/files/TL_N34.pdf.

RATTS, Alex. Os lugares da gente negra: temas geográficos no pensamento de Beatriz Nascimento e Lélia Gonzalez. In: SANTOS, Renato Emerson dos (Org.). Questões urbanas e racismo. Petrópolis: Dp Et Alii, 2012. p. 216-243. (Coleção Negras e Negros: Pesquisas e Debates).

ROLNIK, Raquel. Territórios negros nas cidades brasileiras: etnicidade e cidade em São Paulo e Rio de Janeiro. In: SANTOS, Renato Emerson dos (org.). Diversidade, espaço e relações étnico-raciais: o negro na geografia do Brasil. Belo Horizonte, MG: Autêntica, 2007, p. 75-90.

SACK, Robert. D. O significado de territorialidade. In: DIAS, Leila Christina; FERRARI, Maristela. (Org.). Territorialidades Humanas e Redes Sociais. Florianópolis, Insular, 2011. SANTOS, Milton. A urbanização brasileira. 5. ed. São Paulo: Edusp, 2005. 174 p.

O espaço dividido: os dois circuitos da economia urbana dos países subdesenvolvidos. Tradução de Myrna T. Rego Vianan. Rio de Janeiro: Francisco Alves, 1979.

O espaço do cidadão. São Paulo: Nobel, 1987. 
SANTOS, Renato Emerson dos (Org.). Diversidade, espeço e relações étnico-raciais. Belo Horizonte: Autêntica, 2007.

- Sobre especialidades das relações raciais: raça, racialidade e racismo no espaço urbano. In: SANTOS, Renato Emerson dos Santos. (Org.) Questões Urbanas e Racismo. Petrópolis: DP et Alii; Brasília: ABPN, 2012, p. 36-67. Edição bilíngue. (Coleção Negras e Negros: Pesquisas e Debates)

SILVA, Maria Nilza da. Nem para todos é a cidade: Segregação urbana e racial em São Paulo. Brasília: Fundação Cultural Palmares, 2006. 232 p.

SILVEIRA, María Laura. Novos aconteceres, novas territorialidades. In: DIAS, L. C. e FERRARI, M. (orgs.). Territorialidades Humanas e Redes Sociais. Florianópolis: Insular, 2013. p. 39-62.

SOUZA, Marcelo Lopes de Souza. O território: sobre espaço e poder, autonomia e desenvolvimento. In: CASTRO, Iná Elias de; GOMES; Paulo César da Costa; CORRÊA, Roberto Lobato. Geografia: conceitos e temas. 14 ed. Rio de Janeiro: Bertrand Brasil, 2011, p. $77-116$

TELLES, Edward. Cor da Pele e Segregação Residencial no Brasil. Estudos Afro-Asiáticos No. 24, pp. 5-22. 1993.

VARGAS, João H. Costa. Apartheid brasileiro: raça e segregação residencial no Rio de Janeiro. Revista de Antropologia, São Paulo, v. 48, n. 1, p. 75-131, June 2005. Available from $<$ http://www.scielo.br/scielo.php?script=sci_arttext\&pid=S0034-7701200500 0100003\&lng=en\&nrm=iso $>$. access on 24 Apr. 2017. http://dx.doi.org/10.1590/S003477012005000100003.

WERNECK, Jurema. Racismo Institucional: uma abordagem conceitual. Geledés - Instituto da Mulher Negra. São Paulo, 2013. 